\title{
Temperature Increase and Cotton Crop Phenology
}

\author{
Qunying Luo $^{\mathrm{a}}$, Michael Bange ${ }^{\mathrm{b}}$, Loretta Clancy ${ }^{\mathrm{b}}$ \\ ${ }^{a}$ University of Technology, Sydney, PO Box 123, Broadway, NSW, 2007 \\ ${ }^{b}$ CSIRO Division of Plant Industry, Locked Bag 59, Narrabri, NSW, 2390 \\ Email:qunying.luo@uts.edu.au
}

\begin{abstract}
The daily outputs of the Commonwealth Scientific and Industrial Research Organisation (CSIRO) Conformal Cubic Atmospheric Model driven by four general circulation models (GCMs) were used by a stochastic weather generator, LARS-WG, to construct local climate change scenarios at nine key cotton production areas in eastern Australia. These climate change scenarios were then linked to daily temperaturedriven models of cotton phenology (the CSIRO Cotton Day Degree calculator and the Last Effective Flower tools) to examine the magnitude of the effects of increased temperature on the initiation and duration of key crop phenophases and on the occurrence of heat stress (hot days $\geq 35^{\circ} \mathrm{C}$ maximum) and cold shocks $\left(\leq 11^{\circ} \mathrm{C}\right.$ minimum) during the growing season. The results show that when using 1 Oct. sowing (1) the timing of emergence, 1st square (flower bud), 1st flower and 1st open boll advanced 1 9, 4 13, 5 14, 8 16 days respectively for the period centred on 2030 compared to the period centred on 1990; (2) when crops were planted 10 days earlier, emergence advanced more in most of the locations while other phenological events changed only slightly (approximately 1 day) in comparison with 1st. Oct. sowing; when crops were planted 10 days later all these events generally were delayed (approximately 1.5 days) in comparison with 1st Oct. sowing depending on locations; (3) the timing of the last effective square, last effective flower and last harvestable boll were delayed 7 12, 6 9 and 3 9 days respectively across locations and GCMs; and (4) combining the effects of an earlier time of first square and a later last effective square potentially increased the time for new fruit (squares) to be produced by up to two to three weeks. This analysis highlights the challenges associated with temperature with future climate change for future cotton production in Australia. Future research will be directed to assess the combined effects of changes in temperature, rainfall and atmospheric $\mathrm{CO}_{2}$ concentration on cotton water use, water use efficiency, cotton lint yield, fibre quality (i.e. micronaire and fibre length); evaluate the effectiveness of a range of plant-based and management-based adaptation options in dealing with climate change risks; and quantify the cost and benefits of identified effective adaptation options, especially with the use of high yielding transgenic cotton with early high fruit loads in Australian high yielding ( $>2000 \mathrm{~kg}$ lint $/ \mathrm{ha}$ ) irrigated systems.
\end{abstract}

Keywords: $\quad$ temperature increase, cotton phenology, heat stress, cold shock 


\section{INTRODUCTION}

Temperature is one of the major environment factors affecting the growth, development and yields of crops, especially the rate of development (Luo, 2011). On one hand, crops have basic requirements for temperature to complete a specific phenophase or the whole life cycle. On the other hand, extremely high and low temperatures can have detrimental effects on crop growth, development and yield, particularly at critical phenophases. While cotton is morphologically indeterminate, the rate of many developmental processes such as germination, floral initiation, and development of fruiting bodies is controlled by temperature (Hearn and Constable, 1984). Daily temperature also plays an important role in determining the earliest date of sowing, defining season length which can both influence yield potential and quality (Bange et al., 2008a; Bauer et al., 2000; Dong et al., 2006), and determining where cotton can be produced sustainably. Generally the longer the growing season (GS) the greater the potential for higher lint yields (Bange and Milroy, 2004a; Stiller et al., 2004). In Australian cotton systems, the temperature requirements for the development of cotton are described by the accumulation of degree days calibrated with a base temperature of $12^{\circ} \mathrm{C}$ (Constable and Shaw, 1988). Other cotton systems elsewhere have used a base temperature closer to $15^{\circ} \mathrm{C}$ (Robertson et al., 2007).

Throughout most Australian production systems, minimum temperatures (Tmin) $\left(\leq 11^{\circ} \mathrm{C}\right)$ experienced early in the cotton season can cause delays in development, reduction in growth, and sometimes chilling injury (Constable et al., 1976; Bange and Milroy, 2004b). As the season progresses maximum temperatures $\left(\geq 35^{\circ} \mathrm{C}\right.$, heat stress) are commonplace throughout cotton production regions and may adversely affect growth and development thus affecting water used, yield and fibre quality (Hodges et al., 1993). At the end of a cotton season cooler or cold temperature will influence the timing of crop maturity and impact on the effectiveness of chemical harvest aids, both again directly affecting yield and quality. Cotton has an optimal thermal kinetic window of 23 to $32^{\circ} \mathrm{C}$ in which metabolic activity is most efficient (Burke et al., 1988; Conaty et al., 2012).

Cotton exposed to low temperatures takes longer to develop, and accumulates biomass at a slower rate (Gipson, 1974; Mauney 1986). Cold temperature responses (below $10^{\circ} \mathrm{C}$ ) in early post-emergent seedlings can permanently arrest growth and development (Christiansen, 1967; Christiansen and Thomas, 1969). Bange and Milroy (2004b) also found that negative effects on development exist when plants were exposed to at least 10 nights at $10^{\circ} \mathrm{C}$, or for 5 nights at $5^{\circ} \mathrm{C}$ on post emergent cotton. In Australia, to account for early season cold temperature effects on cotton development, a 'cold shock' effect is applied to day degree (DD) accumulation. A 'cold shock' is defined as an event when the daily minimum temperature falls to $11^{\circ} \mathrm{C}$ or less, which is assumed to cause chilling injury and thus delays development.

Late in the season, cold temperatures $\left(\leq 2^{\circ} \mathrm{C}\right)$ can signal the end of the GS. These low temperatures may force bolls to open affecting lint fibre quality (colour and maturity), and will severely impede the efficacy of chemical harvest aids (optimal temperature $\sim 18^{\circ} \mathrm{C}$ ) to remove leaf from the plant prior to harvest (Bange et al., 2009). The optimum sowing time aims to reduce the incidences of 'cold shocks', while in-season management aims to ensure that fruit has adequate time to mature and that harvest aids are applied prior to the onset of cold temperature.

Increase in temperature associated with climate change will change crop phenology including the start and the duration of phenophases. These changes may have significant implications for cotton lint yield and fibre quality. Hence this work aims to understand local climate change in Australian cotton regions and quantify its impacts on cotton crop phenology.

\section{MATERIALS AND METHODS}

\subsection{Study Locations}

This study focused on major cotton production areas in Queensland (Emerald, Dalby, St George and Goondiwindi) and New South Wales (Moree, Bourke, Narrabri, Warren and Hillston), Australia (Table 1). These cotton production areas also represent different growing environments: with Emerald, Bourke and St George being classified as being hot; Dalby, Goondiwindi, Moree, Narrabri and Warren as being central; and Hillston as cool. Classification of these climates for cotton production was based on the analysis of McMahon and Low (1972) using growing DD. These different environments have resulted in adoption of different crop management practices and cultivars. 
Table 1 Study Locations

\begin{tabular}{|c|c|c|}
\hline Locations & Latitude ( $(\mathrm{S})$ & Longitude ( $\left.{ }^{\circ} \mathbf{E}\right)$ \\
\hline Emerald & 23.55 & 148.24 \\
\hline Dalby & 27.18 & 151.26 \\
\hline St George & 28.04 & 148.58 \\
\hline Goondiwindi & 28.55 & 150.31 \\
\hline Moree & 29.49 & 149.85 \\
\hline Bourke & 30.09 & 145.94 \\
\hline Narrabri & 30.34 & 149.76 \\
\hline Warren & 31.78 & 147.77 \\
\hline Hillston & 33.49 & 145.52 \\
\hline
\end{tabular}

\subsection{Local Climate Change \& Climate Change Scenarios}

In this study, the outputs of the CSIRO Conformal Cubic Atmospheric Model (CCAM), a dynamic downscaling approach, for baseline (1980-1999) and future period (2020-2039) were used by a stochastic weather generator, LARS-WG, to derive local temperature change including changes in the mean and in variability. The CCAM model was driven by four general circulation models (GCMs), specifically GFDL, CSIRO Mark 3.5, MPI, and MIROC, under A2 emission scenario. The local temperature change information for each location were then reapplied to the LARS-WG with the historical daily temperature data to construct long time series $(100 \mathrm{y})$ temperature scenarios including baseline and future scenarios for impact assessment. More information on these procedures can be found in Luo et al (2013).

\subsection{Performance of the LAS-WG}

To have confidence in the performance of the LARS-WG, a statistical t-test was carried out to examine the difference in the mean of observed (historical datasets) and LARS-WG-generated temperature including Tmax and Tmin for the period 1980-1999. The observed climate data were obtained from Specialised Information for Land Owners Patched Point Dataset (http://www.longpaddock.qld.gov.au/silo) (Jeffrey et al., 2001).

\subsection{Cotton Crop Phenology}

Cotton sowing in the Australian industry occurs around 1 Oct. (Bange et al., 2008a). In this analysis, we chose three sowing times: 20 Sep., 1 Oct. and 11 Oct. We then defined the GS as the period from these sowing dates until 21 May, 31 May and 10 Jun respectively. For the central and cool locations these sowing dates generally represent a range of sowing dates currently used.

Cotton crop phenology stages considered in this study include the dates of emergence, first square (flower bud), first flower, first open boll, last effective square (LES), last effective flower (LEF), and last harvestable boll (LHB). The DD targets corresponding to the first four stages are set to 80, 505, 777 and 1527 DD respectively (Constable and Shaw, 1988). The last harvestable boll is associated with the occurrence of the first frost which is defined as the Tmin of $\leq 2^{\circ} \mathrm{C}$. The date of the last effective square, flower, and boll can be used to determine target 'cutout' dates that assist in ceasing production of new fruiting sites to allow crops (and all bolls) to be mature in time for harvest. The DD differences between the dates of the LHB and LEF (LHB period) and between the LEF and LES (square period) are set to 750 and 430 degree days respectively (Constable, 1991). The DD were derived using a base temperature of $12^{\circ} \mathrm{C}$ (Constable and Shaw, 1988).

As mentioned in the Introduction, to account for cold temperature on early season cotton development a 'cold shock' effect is applied to DD accumulation for predicting the first square and first flower. A 'cold shock' is defined as an event when daily Tmin falls to $11^{\circ} \mathrm{C}$ or less, and extends the DD accumulation by 5.2 degree days for each cold shock event (Hearn and Constable, 1984).

To quantify the effects of climate change on crop phenology, the on-line Day Degree calculator and Last Effective Flower tools (http://cottassist.com.au), developed by CSIRO, were modified to be used with baseline (1980-1999) and future period (2020-2039) temperature scenarios for the study locations. Changes in cotton phenology were presented in multi-model ensemble means, which is the average derived from the four driving GCMs. 


\section{RESULTS}

\subsection{Performance of the LARS-WG}

Table 2 shows the p-values associated with t-tests comparing the mean monthly values of Tmax and Tmin between observed and LARS-WG modelled data for the 1980-1999 time period. It can be seen that the overwhelming majority (about $95 \%$ of cases across locations, months and temperature variables) has p-values of greater than 0.05 , indicating that the LARS-WG performs reasonably well in simulating monthly mean Tmax and Tmin. This demonstrated the robustness of the weather generator used in this study.

Table 2 p-values associated with t-tests between the mean values of monthly temperatures calculated from daily observed and modelled temperatures using the LARS-WG. The bold values in the table highlight the instances where there were significant differences $(\mathrm{p} \leq 0.05)$ between the observed and predicted data.

\begin{tabular}{|c|c|c|c|c|c|c|c|c|c|c|c|c|c|}
\hline Locations & & Jan & Feb & Mar & Apr & May & Jun & Jul & Aug & Sep & Oct & Nov & Dec \\
\hline \multirow[t]{2}{*}{ Emerald } & $\mathrm{T}_{\min }{ }^{1}$ & 0.610 & 0.574 & 0.418 & 0.865 & 0.718 & 0.398 & 0.465 & 0.570 & 0.586 & 0.666 & 0.482 & 0.513 \\
\hline & $\mathrm{T}_{\max }^{2}$ & 0.983 & 0.716 & 0.602 & 0.811 & 0.911 & 0.077 & 0.941 & 0.471 & 0.073 & 0.044 & 0.248 & 0.852 \\
\hline \multirow[t]{2}{*}{ Dalby } & $\mathrm{T}_{\min }$ & 0.689 & 0.491 & 0.130 & 0.745 & 0.716 & 0.855 & 0.418 & 0.790 & 0.314 & 0.890 & 0.868 & 0.873 \\
\hline & $\mathrm{T}_{\max }$ & 0.328 & 0.233 & 0.881 & 0.324 & 0.735 & 0.373 & 0.973 & 0.045 & 0.029 & 0.258 & 0.952 & 0.875 \\
\hline \multirow[t]{2}{*}{ St George } & $\mathrm{T}_{\min }$ & 0.647 & 0.739 & 0.859 & 0.181 & 0.695 & 0.265 & 0.586 & 0.750 & 0.131 & 0.071 & 0.155 & 0.353 \\
\hline & $\mathrm{T}_{\max }$ & 0.768 & 0.530 & 0.932 & 0.089 & 0.648 & 0.684 & 0.747 & 0.725 & 0.045 & 0.006 & 0.076 & 0.269 \\
\hline \multirow[t]{2}{*}{ Goondiwindi } & $\mathrm{T}_{\min }$ & 0.972 & 0.454 & 0.401 & 0.675 & 0.908 & 0.182 & 0.748 & 0.706 & 0.1 & 0.701 & 0.426 & 0.441 \\
\hline & $\mathrm{T}_{\max }$ & 0.488 & 0.878 & 0.719 & 0.869 & 0.198 & 0.955 & 0.635 & 0.252 & 0.015 & 0.055 & 0.119 & 0.467 \\
\hline \multirow[t]{2}{*}{ Moree } & $\mathrm{T}_{\min }$ & 0.426 & 0.833 & 0.630 & 0.197 & 0.862 & 0.600 & 0.725 & 0.103 & 0.210 & 0.529 & 0.246 & 0.944 \\
\hline & $\mathrm{T}_{\max }$ & 0.318 & 0.648 & 0.307 & 0.730 & 0.522 & 0.662 & 0.410 & 0.714 & 0.111 & 0.082 & 0.199 & 0.274 \\
\hline \multirow[t]{2}{*}{ Bourke } & $\mathrm{T}_{\min }$ & 0.900 & 0.784 & 0.429 & 0.211 & 0.226 & 0.304 & 0.405 & 0.910 & 0.180 & 0.050 & 0.110 & 0.186 \\
\hline & $\mathrm{T}_{\max }$ & 0.826 & 0.455 & 0.538 & 0.727 & 0.928 & 0.684 & 0.091 & 0.532 & 0.079 & 0.124 & 0.174 & 0.667 \\
\hline \multirow[t]{2}{*}{ Narrabri } & $\mathrm{T}_{\min }$ & 0.474 & 0.796 & 0.963 & 0.174 & 0.030 & 0.771 & 0.732 & 0.736 & 0.828 & 0.475 & 0.456 & 0.947 \\
\hline & $\mathrm{T}_{\max }$ & 0.637 & 0.477 & 0.829 & 0.743 & 0.534 & 0.701 & 0.802 & 0.239 & 0.038 & 0.040 & 0.169 & 0.375 \\
\hline \multirow[t]{2}{*}{ Warren } & $\mathrm{T}_{\min }$ & 0.301 & 0.966 & 0.756 & 0.219 & 0.350 & 0.613 & 0.528 & 0.880 & 0.828 & 0.244 & 0.138 & 0.547 \\
\hline & $\mathrm{T}_{\max }$ & 0.649 & 0.612 & 0.510 & 0.782 & 0.884 & 0.846 & 0.965 & 0.701 & 0.314 & 0.413 & 0.063 & 0.875 \\
\hline \multirow[t]{2}{*}{ Hillston } & $\mathrm{T}_{\min }$ & 0.403 & 0.908 & 0.267 & 0.123 & 0.590 & 0.338 & 0.931 & 0.960 & 0.951 & 0.304 & 0.150 & 0.660 \\
\hline & $\mathrm{T}_{\max }$ & 0.866 & 0.036 & 0.122 & 0.580 & 0.453 & 0.670 & 0.809 & 0.838 & 0.352 & 0.205 & 0.104 & 0.159 \\
\hline
\end{tabular}

\subsection{Temperature change}

Figure 1 shows the multi-model ensemble mean changes between the periods centred on 2030 and 1989 in Tmean for GS and for each location. From this figure it can be seen that Tmean increased $1 \sim 1.2^{\circ} \mathrm{C}$ across locations. The largest change in average temperature occurred in Dalby associated with a considerable shift in both Tmax and Tmin. The least change in Tmean was at Hillston associated with the lowest changes in both Tmax and Tmin across locations.

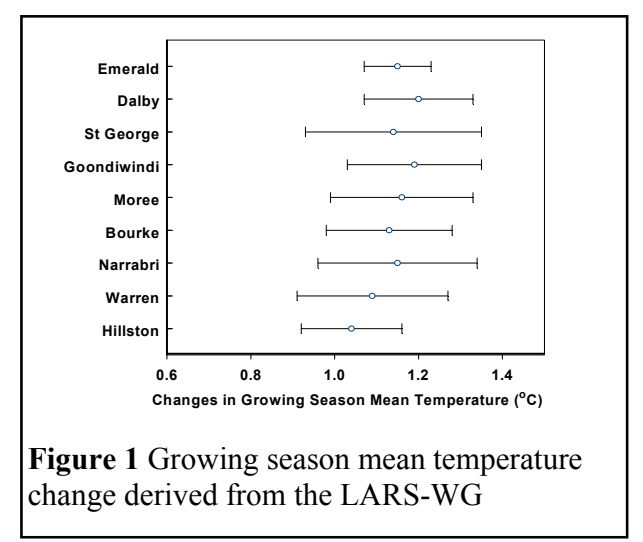

\subsection{Changes in crop phenology}

Normal sowing

Figure 2 shows the multi-model ensemble mean changes in key phenological events for the period centred on 2030 in comparison with the baseline period 1980-1999. From this figure, it can be seen that temperature increase accelerated the phenological development of all phases across all locations. Emergence, first square, first flower, and first open boll individually were advanced 1 9, 2 8,1 2, and 1 5 days, respectively (Figure 2a). The biggest changes were in the period from sowing to emergence, especially for the locations further south. In general the smallest effect across all phases was associated with the most northern growing region of Emerald, while the largest change for all phases was associated with the most southern growing areas of Warren and Hillston. This translated into the smallest overall cumulative change for Emerald ( $8 \mathrm{~d})$ and greatest change for Hillston and Warren (16 d). 
For the end of season, the timing of the phenological stages of the LES, LEF and LHB were delayed 0.3 3, 1.8 6.8 and 2.5 9 days respectively across locations, except Warren where the LEF was unaffected and St George where the LHB advanced slightly (Figure $2 \mathrm{~b}$ ). The greatest variability in delays was associated with the LHB (at Tmin $\leq 2^{\circ} \mathrm{C}$ ) with the largest changes projected for Warren (9d), followed by Dalby (7d) and Narrabri (6d). The smallest changes for LHB were for St George (-0.3d) and Bourke (2.5d). Across all locations, LES and LEF were also later as the periods between LHB to LEF, and LEF to LES were shorter. Overall this meant that the smallest overall delays in season end were for Bourke (6.5d), Hillston (7.3d) and St George (7.5d). The projected longest delays in season end was for Dalby (11.8d) followed by Moree (10d).

\section{Earlier sowing and Later Sowing}

With earlier sowing (21st Sept.) in comparison with 1st Oct. sowing, emergence advanced by 1 3d or was unchanged across locations except for St George where a 3d delay was found (Table 3). First square was advanced by $1 \sim 4 \mathrm{~d}$ in northern cotton production areas (with warmer climate), but was delayed $\sim 1 \mathrm{~d}$ in southern areas (with colder climate). In general there was little effect by the 1st open boll as there was no more than 1d advancement or delay (Table 3). With later sowing (11th Oct.) in comparison with 1 st Oct. sowing, emergence was delayed $1 \sim 4 \mathrm{~d}$ except at Hillston where a $0.3 \mathrm{~d}$ advancement was found. First square was advanced by $1 \sim 2 \mathrm{~d}$ in warmer locations while delayed $0.3 \sim 3 \mathrm{~d}$ in colder locations. 1st flower and 1st open boll were advanced or delayed in the range of $0 \sim 1.5 \mathrm{~d}$ depending on locations (Table 3).

Table 3 Changes (days) in early phenological events of an earlier (21 Sep.) and later sowing (11 Oct) in comparison with 1 Oct. sowing in a changing climate

\begin{tabular}{lllll}
\hline Locations & Emergence & $\begin{array}{l}\mathbf{1}^{\text {st }} \\
\text { Square }\end{array}$ & $\begin{array}{l}\mathbf{1}^{\text {st }} \\
\text { Flower }\end{array}$ & $\begin{array}{l}\mathbf{1}^{\text {st }} \text { Open } \\
\text { Boll }\end{array}$ \\
\hline Earlier Sowing & & & & \\
\hline Hillston & -1.5 & 0.8 & 0.5 & -0.5 \\
Warren & -1.0 & 0.0 & 0.3 & -0.3 \\
Narrabri & -1.5 & 0.8 & 0.5 & 0.0 \\
Bourke & -3.0 & 0.5 & -0.5 & 0.5 \\
Moree & -2.3 & 0.8 & 0.3 & 0.0 \\
Goondiwindi & 0.0 & -2.0 & 0.5 & 0.5 \\
St George & 3.0 & -3.8 & -0.8 & 1.0 \\
Dalby & -1.5 & -0.5 & 0.5 & 0.5 \\
Emerald & 0.0 & -0.8 & 0.8 & -0.3 \\
\hline Later Sowing & & & & \\
\hline Hillston & -0.3 & 0.3 & 1.3 & -1.5 \\
Warren & 0.0 & 2.8 & 0.8 & -0.8 \\
Narrabri & 2.8 & 0.3 & -0.5 & 0.0 \\
Bourke & 2.3 & -1.0 & -0.5 & -0.3 \\
Moree & 4.0 & -1.5 & 0.3 & -0.3 \\
Goondiwindi & 0.5 & 0.5 & -0.5 & 1.0 \\
St George & 2.3 & 0.0 & -0.5 & 0.5 \\
Dalby & 3.3 & -1.5 & -0.5 & 0.0 \\
Emerald & 0.5 & -0.5 & 0.5 & -0.3 \\
\hline
\end{tabular}

Table 4 Change in the length of fruiting period (the difference in days between the first square to last effective square)

\begin{tabular}{llll}
\hline Locations & $\begin{array}{l}\text { Earlier } \\
\text { sowing }\end{array}$ & $\begin{array}{l}\text { Normal } \\
\text { sowing }\end{array}$ & $\begin{array}{l}\text { Later } \\
\text { sowing }\end{array}$ \\
\hline Hillston & 19.5 & 18.8 & 18.8 \\
Warren & 22.0 & 21.0 & 18.3 \\
Narrabri & 18.5 & 17.8 & 14.8 \\
Bourke & 15.8 & 13.3 & 12.0 \\
Moree & 18.5 & 17.0 & 14.5 \\
Goondiwindi & 16.8 & 14.8 & 13.8 \\
St George & 16.8 & 16.0 & 13.8 \\
Dalby & 20.5 & 18.5 & 16.8 \\
Emerald & 13.8 & 13.0 & 13.0 \\
& & &
\end{tabular}

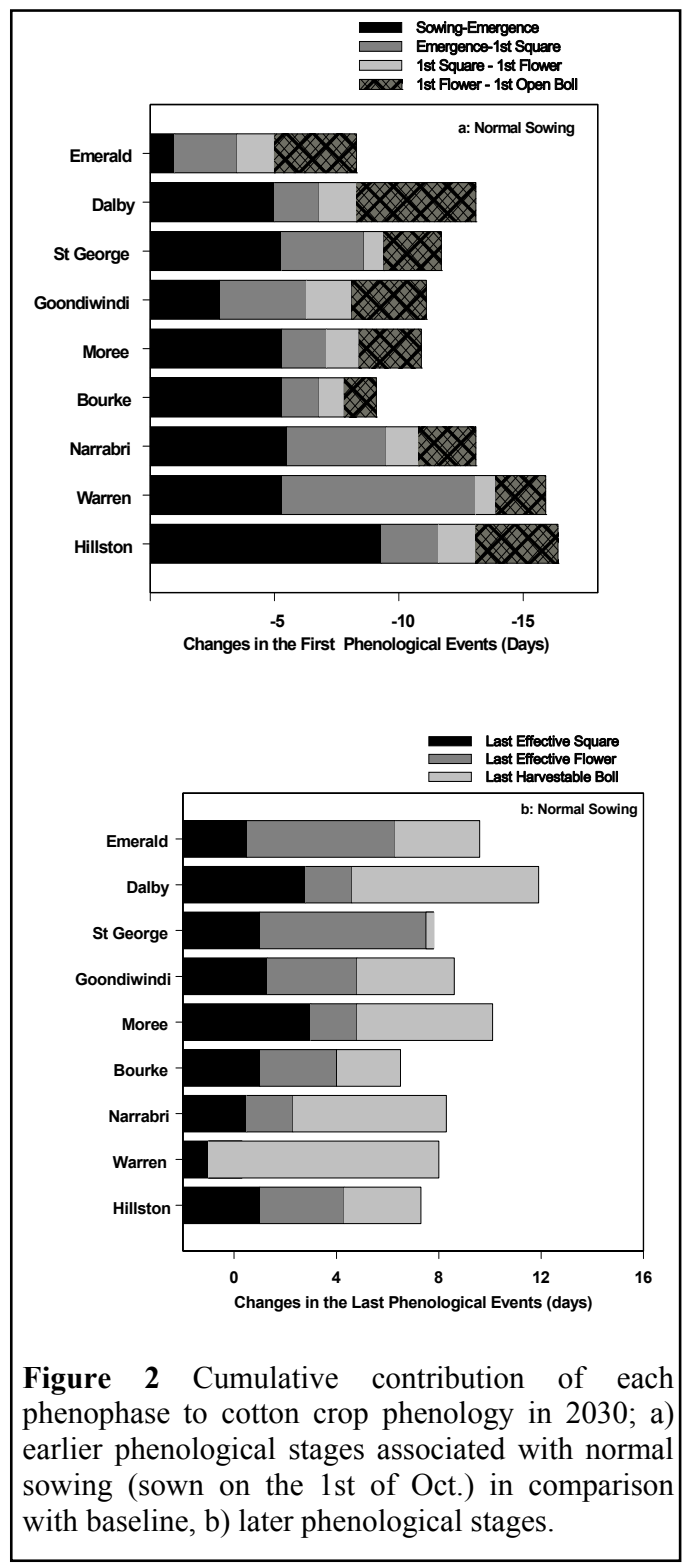




\section{DISCUSSION AND CONCLUSIONS}

These results show that the start of key phenological events such as the emergence, first square, first flower and first open boll advanced across locations and GCMs (Figure 2a). Positive impacts on changes in development were related to advancement in emergence and a potential increase in the reproductive (fruiting) period as a result of earlier first square and delayed last effective square. The delay in the last effective square was a result of both a delay in the onset of first frost $\left(\leq 2^{\circ} \mathrm{C}\right)$ event in the autumn and a more rapid increase in boll development.

Advancement in germination at all locations will lead to increased crop vigour and allows crops to be better established with a more flexible sowing window (Bange et al., 2008b; Braunack et al., 2012). The period from first square to last effective square is effective the period when fruit is developed. This study showed that the period (Table 4) could be increased by two to three weeks, which would result in increased fruit production. Earlier sowing increased the period $1 \sim 2$ days while later sowing reduced the period $0 \sim 3$ days (Table 4).

Potential negative effects associated with changes in development may be associated with reductions in the time for vegetative growth to support reproductive growth, and a loss of reproductive capacity associated with reduced boll filling periods and increase fruit shedding from high temperature-stress days. For first square and first flower a more rapid advancement in all locations means that reproductive growth will occur earlier, placing greater demands on overall growth. If less vegetative growth is produced without proper management or cultivars to suit, this may cause crops to 'cutout' more quickly and reduce yield potential. Reduction in the time to 'cutout' will bring on earlier maturity, thus reducing yield (Bange and Milroy, 2004b). There was also evidence that boll periods will be less as demonstrated by the periods from first flower to first open boll and from last effective flower to last harvestable boll. This is a similar finding to Reddy et al. (1999) where cotton boll development was shortened. As a consequence, fibre properties were influenced and boll size was smaller. Despite potential increases in the fruiting periods which may result in more fruit (bolls) the impact on yield maybe tempered by the reductions in boll size.

Future research will be directed to (1) assess the combined effects of changes in temperature, rainfall and atmospheric $\mathrm{CO}_{2}$ concentration on cotton water use, water use efficiency, cotton lint yield, and fibre quality; (2) evaluate the effectiveness of a range of plant-based and management-based adaptation options in dealing with climate change risks; and (3) quantify the cost and benefits of identified effective adaptation options.

\section{Acknowledgement}

We thank Drs McGregor and Nguyen, CSIRO Marine and Atmospheric Research for providing us the high resolution climate change projections from four GCMs and Mr Chris Bull for putting extracted data onto the tape. Thanks also go to Dr Semenov, Rothamsted Research, UK for providing us the weather generator, LARS-WG, and Mr Peter Devoil for letting us access long times series of historical climate datasets. This project is financially supported by the Cotton Research and Development Corporation with project number: UTS1301.

\section{REFERENCES}

Bange, M.P. and Milroy, S.P. (2004a). Impact of short term exposure to cold temperatures on early development of cotton (Gossypium hirsutum L.). Australian Journal of Agricultural Research $55655-$ 664.

Bange, M.P. and Milroy, S.P. (2004b). Growth and dry matter partitioning of diverse cotton genotypes. Field Crops Research 87 73-87.

Bange, M.P., Caton, S. J. and Milroy, S.P. (2008a). Managing yields of high fruit retention in transgenic cotton (Gossypium hirsutum L.) using sowing date. Australian Journal of Agricultural Research 59, 733741.

Bange, M.P., McRae, D. and Roth, G. (2008b). Cotton. Chapter 3. pp.71-93. In: C.J. Stokes \& S.M. Howden. An overview of climate change adaptation in Australian primary industries - impacts, options and priorities. Canberra, Australia.

Bange, M.P., G.A. Constable, S.G. Gordon, G.R.S. Naylor, and M.H.J. Van der Sluijs, (2009). Importance of fibre quality. p. 30-42. In M.P Bange et al. (ed.) FIBREpak A guide to improving Australian cotton fibre quality. CSIRO and the Cotton Catchment Communities Coop. Research Centre, Narrabri, NSW, Australia. 
Bauer, P.J., Frederick, J.R., Bradow, J.M., Sadler, E.J. and Evans, D.E. (2000). Canopy photosynthesis and fiber properties of normal- and late-planted cotton. Agronomy Journal 92 518-523.

Braunack, M.V., Bange, M.P. and Johnston, D.B. (2012). Can planting date and cultivar selection improve resource use efficiency of cotton systems? Field Crops Research 137 1-11.

Burke, J.J., J.R. Mahan, and J.L. Hatfield. (1988). Crop-specific thermal kinetic windows in relation to wheat and cotton biomassproduction. Agronomy Journal 80 553-556.

Christiansen, M.N. (1967). Periods of sensitivity to chilling in germination cotton. Plant Physiology $42431-$ 433.

Christiansen, M.N., and Thomas, R.O. (1969). Season-long effects of chilling treatments applied to germinating cottonseed. Crop Science $9672-673$.

Conaty, W.C., Burke, J.J., Mahan, J.R., Neilsen, J.E. and Sutton, B.G. (2012). Determining the optimum plant temperature of cotton physiology and yield to improve plant-based irrigation scheduling. Crop Science 52 1828-1836.

Constable G.A., Harris N.V. and Paull R.E. (1976). The effect of planting date on the yield and some fibre properties of cotton in the Namoi Valley. Australian Journal of Experimental Agricultural and Animal Husbandry 16, 265-271.

Constable, G.A. 1991. Mapping the production and survival of fruit on field grown cotton. Agron. J. 83:374378.

Constable, G.A., and Shaw, A.J. (1988). Temperature requirements for cotton. Agfact P5.3.5. Division of Plant Industries, New South Wales Department of Agriculture.

Dong, H., Li, W., Tang, W., Li, Z., Zhang, D., and Niu, Y. (2006). Yield, quality and leaf senescence of cotton grown at varying planting dates and plant densities in the Yellow River Valley of China. Field Crops Research 98 106-115.

Gipson, J.R. (1974). Effect of temperature and methyl parathion on vegetative development and fruiting of the cotton plant. Agronomy Journal 66 337-341.

Hearn, A.B., and Constable, G.A. (1984). Cotton. In 'The physiology of tropical field crops'. (Eds PR Goldsworthy, NMFisher) pp. 495-527. (John Wiley and Sons Ltd: Chichester, UK).

Hodges, H.F., K.R. Reddy, J.M. McKinion, and V.R. Reddy. (1993). Temperature effects on cotton. p. 1-15. Mississippi Agricultural \& Forestry Experiment Station, Mississippi State, MS

Jeffrey, S.J., J.O. Carter, K.B. Moodie, and A.R. Beswick. 2001. Using spatial interpolation to construct a comprehensive archive of Australian climate data. Environmental Modelling and Software 16:309-330.

Luo, Q. (2011). Temperature Thresholds and Crop Production: A Review. Climatic Change 109 (3), 583598.

Luo, Q., Wen, L., McGregor, J. L. and Timbal, B.: 2013, A Comparison of Downscaling Techniques in the Projection of Local Climate Change and Wheat Yields. Climatic Change 120 (1) 249-261.

Mauney, J.R. (1986). Vegetative growth and development of fruiting sites. In 'Cotton physiology'. (Eds JR Mauney, J McD Stewart) pp. 11-28. (Cotton Foundation: Memphis, TN)

McMahon, J. and Low, A. (1972). Growing degree days as a measure of temperature effects on cotton. Cott. Gr. Rev. 49:39-49.

Reddy, K.R., G.H. Davidonis, A.S. Johnson, and B.T. Vinyard, (1999). Temperature regime and carbon dioxide enrichment alter cotton boll development and fiber properties. Agronomy Journal 91, 851-858.

Robertson, B., Bednarz, C., and Burmester, C. (2007). Growth and Development - First 60 days. Cotton Physiology Today. Newsletter of the Cotton Physiology Education Program - National Cotton Council. 13(2).

Stiller, W.N., P.E. Reid, and G.A. Constable. (2004). Maturity and leaf shape as traits influencing cotton cultivar adaptation to dryland conditions. Agronomy Journal 96 656-664. 